\title{
Geo-informatics Techniques for Assessing Physiological Status and Productivity of RRIC 121 Genotype of Hevea brasiliensis (Rubber) under Different Harvesting Systems
}

\author{
K.M.E.P. Fernando ${ }^{1 *}$, H.M.R. Premasiri ${ }^{2}$, K.V.V.S. Kudaligama ${ }^{3}$ \\ ${ }^{1}$ Department of Botany, University of Sri Jayewardenepura, Sri Lanka \\ ${ }^{2}$ Department of Department of Earth Resources Engineering, University of Moratuwa, Sri Lanka \\ ${ }^{3}$ Department of Biochemistry and Physiology, Rubber Research Institute of Sri Lanka
}

Date Received: 23-11-2016

Date Accepted: 25-12-2016

\begin{abstract}
Rubber (Hevea brasiliensis) one of the main plantation crops in Sri Lanka is the only plant species cultivated commercially for natural rubber harvesting. Novel systems for harvesting have been introduced but spatial distribution of photosynthetic potential determining key factor for sustainable cultivation has not been properly explored. Use of such techniques such as Satellite Remote Sensing (RS) and Geographic Information System (GIS) to analyse spatial and biological factors related to the productivity of rubber plantation with different harvesting systems is the main objective of the present study.

Quikebird high resolution satellite images were used for RS analysis. Chlorophyll content of rubber leaves was measured using a SPAD-502 chlorophyll meter. Chlorophyll content and satellite images were analysed using GIS and spatial statistical methods to determine the variation in different harvesting systems. Yield data were collected from the study site and yield parameters were correlated with chlorophyll content and Normalized Difference Vegetation Index (NDVI) values. Results revealed all systems exhibited promising yield performance without significant deviation but slightly higher yield per hectare per year (YPH) and dry rubber content of latex (DRC) were recorded in quarter spiral based once in three days $(\mathrm{S} / 3 \mathrm{~d} 4)$ and weekly $(\mathrm{S} / 2 \mathrm{~d} 12 \mathrm{~d} 7)$ harvesting systems. Chlorophyll content and rubber yield showed direct correlation in all systems. NDVI vs chlorophyll showed positive correlation $r^{2}=0.65$ and spatial distribution of chlorophyll and NDVI values demonstrated sound physiological status of plants across the plantation with different harvesting systems. Cost effective LIH systems showed better production trend demonstrating relatively higher yield while reducing tapping cost and labour. Satellite based remote sensing technique is an easy and efficient tool to estimate productivity of rubber plantation over a large area.
\end{abstract}

Keywords: Chlorophyll, NDVI, harvesting, Remote Sensing, Rubber.

\section{Introduction}

Rubber (Hevea brasiliensis) is the only plant species commercially planted for natural rubber production and being the second largest plantation crop in Sri Lanka. Rubber established as plantation crop in the Wet zone and certain region of intermediate zone of Sri Lanka and is being extended to non-traditional areas especially in Moneragala, Ampara, Vaunia and Mulathivu districts. Rubber and allied products are one of major export earnings in Sri Lanka contributes immensely to country's economy. Rubber cultivation aims at latex

*Correspondence: preenikmep@yahoo.com

Tel: +94112758427

ISSN 2235-9370 Print/ISSN 2235-9362 Online (C) University of Sri Jayewardenepura 
yield, and it is a long term investment that has about 30 years of economic lifespan. Other than that increasing demand for timber and potential to value of its carbon sequestering capacity through carbon trading are added remarkable benefits.

\section{Latex harvesting}

High level of bark consumption is a prime factor for shortening the economic lifespan of the tree. Locote et al. (2004) and Vijayakumar (2003) reported the application of short cut exploitation system to increase the yield of rubber trees. Additionally, shortage of skilled harvesters is another key issue in the rubber industry. Labour saving technologies while maintaining the latex yield have been introduced to overcome labour related issues by reducing tapping frequency (Sivakumaran et al., 1991; Johari et al., 1993; Sivakumaran et al., 1993; Rodrigo et al., 2004;). Reducing the harvesting intensity provides a practical solution to key issues associated with natural rubber industry (Rodrigo et al., 2012). Low intensity harvesting systems reduce the harvester requirement per plantation and enhance the economic lifespan of rubber trees (Nugawela et al., 2000; Rodrigo et al., 2004; Rodrigo, et al., 2011). Different combinations of harvesting frequencies and cut lengths along with different stimulation strategies have been assessed for latex yield and found low intensity harvesting (LIH) systems reduced the harvesting cost and increased the profitability of rubber plantations (Kudaligama, 2013; Kudaligama et al., 2013)

\section{Spectral analysis of chlorophyll}

Factors that govern and parameters that indicate the efficiency of photosynthetic productivity under field conditions could be used as tools in the selection of Hevea genotypes (Rodrigo, 2007). Nugawela et al. (1995) screened the yield potential of some Hevea genotypes using photosynthetic parameters to establish a method for early screening.

Remote sensing is an effective and efficient technique for updating and analyzing the dynamics of plantations through the multispectral satellite data. Chlorophyll concentration is related to the photosynthetic potential and the productivity of the plant and an indirect indicator for physiological status of the plant (Danks et al., 1983; Gamon and Surfus, 1999). Several studies on different vegetation types found a correlation between reflectance-based Normalized Difference Vegetation Index (NDVI) and chlorophyll content at leaf scale (Jones et al., 2007; Yoder and Pettigrew, 1995) and canopy scale (Coops et al., 2003; Yoder and Waring, 1994). Analysing leaf area index of rubber plantation and its dynamics by remote sensing is of great significance in predicting yield and evaluating tapping intensity (Chen et al., 2015).

Multicriteria analysis and data acquisition through satellite Remote Sensing technology are promising methods to analyse spatial distribution of key factors which govern the yield and productivity in response to different harvesting systems. Studies on analysis of latex yield in different harvesting systems in relation to canopy characteristics including photosynthetic potential of rubber have not been carried out in Sri Lanka. This study aims to apply Geo-spatial analysis along with RS techniques to analyse determining factors for physiological status and productivity to make sustainable rubber industry in Sri Lanka. 


\section{Materials and Methods}

\subsection{Study Area}

Rubber plantations of Kuruwita Substation of Rubber Research Institute of Sri Lanka (RRISL) which lies in the WL 1a agro-ecological zone with average annual rainfall about $3200 \mathrm{~mm}$ was selected for the study. The study site is located in Rathnapura district in Sabaragamuwa Province in low elevated topographic terrain showing nearly flat ground (Figure 1). The experimental field had been replanted in 2002 with RRIC 121 genotype with paired row system: distance between the pair is $3 \mathrm{~m}$ and the distance between two paired rows is $13 \mathrm{~m}$.

Primary and secondary data were used for the analyses in this research. Field and laboratory data such as yield data, in-situ test data, chlorophyll analysis data etc. were obtained as primary data. Sampling locations and other ground data were taken using GPS coordinates. High resolution Remote Sensing data; Quikebird images were used as secondary data. Yield data in four experimental plots practising different harvesting systems (Table 1) were obtained during the period from January 2012 to October 2016.
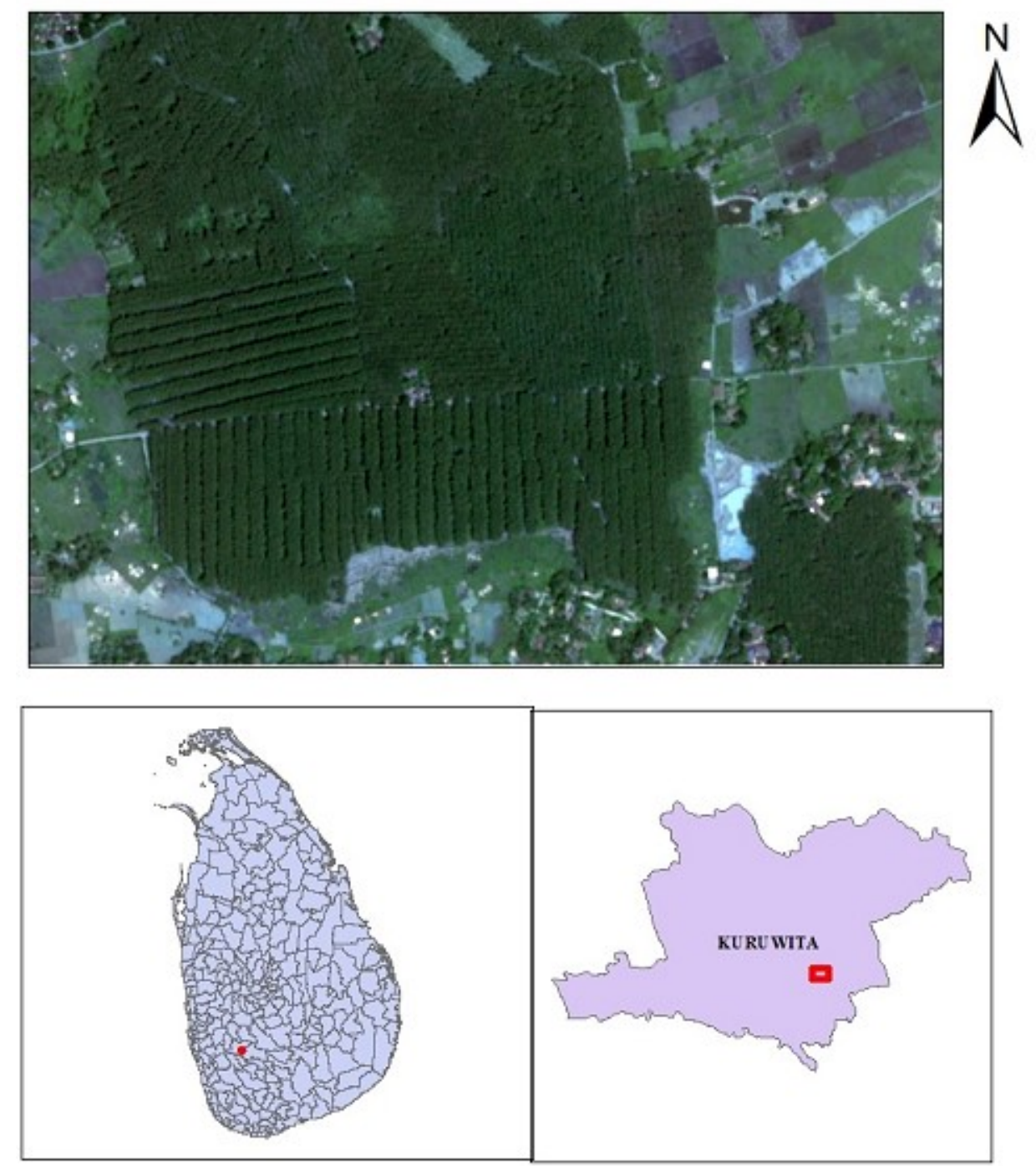

Figure 1: Location map of rubber plantations in Kuruwita. 
Table 1: Four latex harvesting systems practising in Kuruwita experimental site.

\begin{tabular}{lllll}
\hline $\begin{array}{l}\text { Harvesting } \\
\text { system }\end{array}$ & \multicolumn{2}{l}{ Tapping method and frequency } & System & \\
\hline $\mathrm{S} / 2 \mathrm{~d} 2$ & $\begin{array}{l}\text { Half spiral based once in two days } \\
\text { frequency }\end{array}$ & $\begin{array}{l}\text { Traditional } \\
\text { system }\end{array}$ & harvesting \\
$\mathrm{S} / 2 \mathrm{~d} 4$ & $\begin{array}{l}\text { Half spiral based once in four days } \\
\text { frequency }\end{array}$ & & \\
& & & & \\
$\mathrm{S} / 4 \mathrm{~d} 3$ & $\begin{array}{l}\text { Quarter spiral based once in three days } \\
\text { frequency }\end{array}$ & System (LIH) & Harvesting \\
$\mathrm{S} / 2 \mathrm{~d} 12 \mathrm{~d} / 7$ & $\begin{array}{l}\text { Half spiral based two consecutive days per } \\
\text { week frequency }\end{array}$ & & \\
\hline
\end{tabular}

\subsection{Measurement of the Yield}

The amount of latex yield harvested from experimental plots was expressed as follows.

Daily dry rubber yield per tree (GTT-g)

Daily dry rubber yield was calculated using the intake per harvester and number of trees tapped. Daily dry rubber yield per tree $(\mathrm{g})=$ intake per harvester $(\mathrm{g}) / \mathrm{Number}$ of trees harvested.

Yield per hectare per year (YPH-kg/ha/y)

Yield per hectare per year was calculated using the average daily dry rubber yield of tree, number of annual tapping days and tree density per hectare.

Dry rubber content of latex percentage (DRC \%)

Latex sample was diluted with two fold of water, mixed well and poured into a cylinder. The reading was taken on the stem of the metrolac immersed in latex. Then the percentage of dry matter content was determined using the Ready-reckoner chart used in determination of $\mathrm{DRC} \%$ using the Metrolac.

\subsection{Determination of Leaf Chlorophyll Content}

SPAD-502 chlorophyll meter was used to measure relative chlorophyll content in rubber leaves non-destructively in the field. Randomly selected six trees (average of 24 values per tree) from each plot were measured for chlorophyll measurements. Standard method developed by Arnon (1949) was used to quantify total chlorophyll content of rubber leaves. Locations of the sample trees and boundaries of blocks with different harvesting systems were recorded using hand held GPS.

\subsection{Remote Sensing and GIS Analysis}

High resolution satellite images were used for this study and image time was selected based on the availability of the images and our sampling time. Quikebird World View 2 image was used for this study (date of the image was 02.05.2013).

Satellite images were processed using basic tools available in ARC GIS 10.2 software and Normalized Difference Vegetation Index (NDVI) was estimated. NDVI is used to estimate the portion of photosynthetically active radiation absorbed by the crop canopy. The prepared 
NDVI images were classified into 7 classes by re-coding of pixels. This tool is commonly used to indicate the amount of vegetation in an image, and to differentiate vegetated and nonvegetated areas.

NDVI was calculated using Quikebird satellite images, and the formula for NDVI is given in equation 1.

$\mathrm{NDVI}=(\mathrm{NIR}-\mathrm{Red}) /(\mathrm{NIR}+\mathrm{Red})$

NDVI maps were analysed along with in situ chlorophyll data. All data layers were spatially analysed using spatial analyst and spatial statistical tools.

\section{Results}

\subsection{NDVI analysis}

NDVI map in the area shows some variation in NDVI values from 0.0 to 0.90 within the blocks and experimental plots are completely covered by rubber canopy. However, within the canopy and rows some variation in NDVI values was observed. Direction of the row of trees and sun angle affected the NDVI values and remarkable difference in different harvesting systems could not be observed (Figure 2).

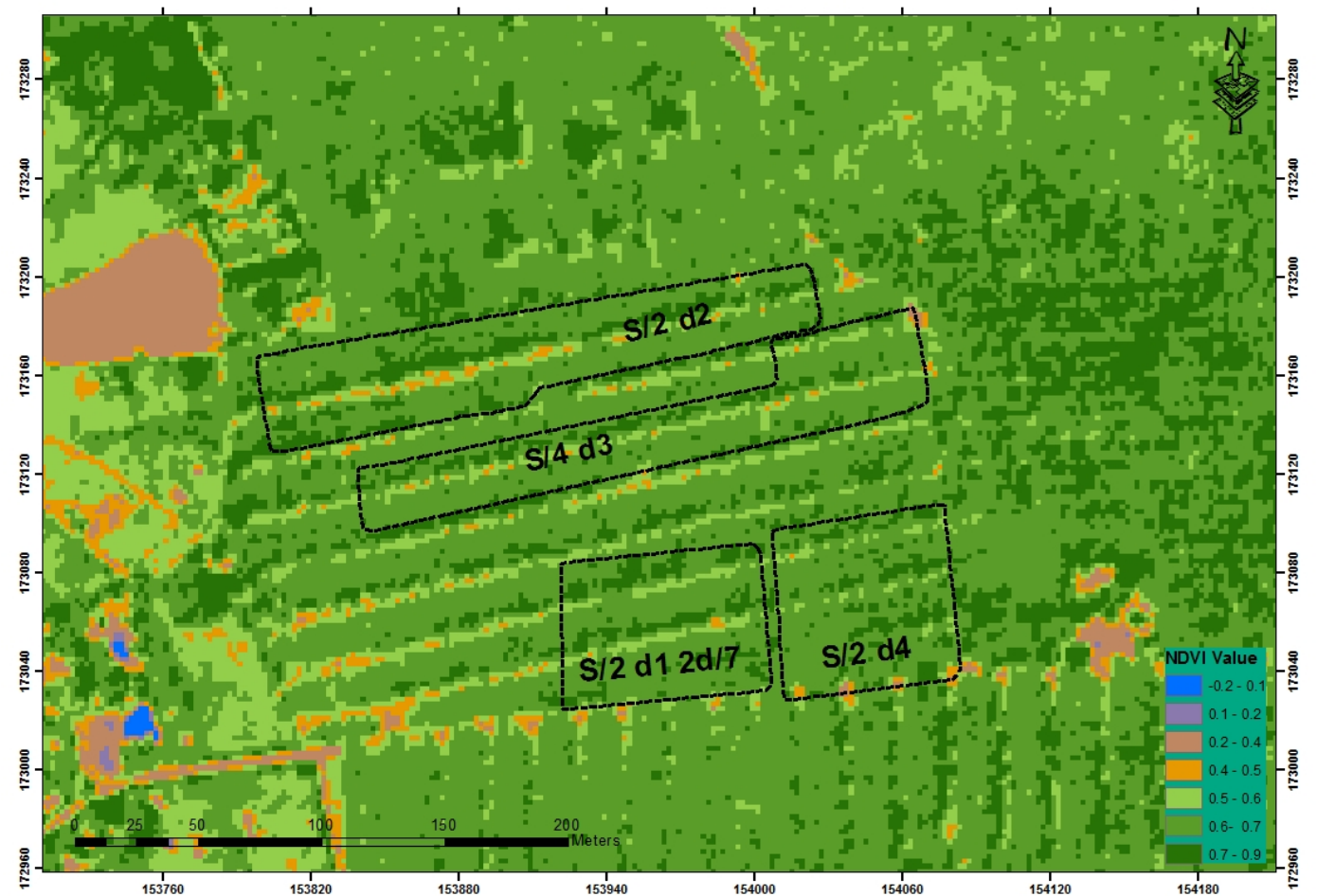

Figure 2: NDVI map showing four blocks having different harvesting systems; $\mathrm{S} / 2 \mathrm{~d} 2$, $\mathrm{S} / 4 \mathrm{~d} 3, \mathrm{~S} / 2 \mathrm{~d} 4$ and $\mathrm{S} / 2 \mathrm{~d} 12 \mathrm{~d} / 7$.

Chlorophyll content in leaves was slightly higher in trees harvested by low frequency harvesting systems and the highest was recorded in $\mathrm{S} / 2 \mathrm{~d} 12 \mathrm{~d} / 7$ system compared to other systems such as $\mathrm{S} / 2 \mathrm{~d} 2, \mathrm{~S} / 4 \mathrm{~d} 3$ and $\mathrm{S} / 2 \mathrm{~d} 4$ (Figure 4). However, the difference was not 
significant between different harvesting systems. The relationship between NDVI values and measured chlorophyll content was linear in rubber leaves at Kuruwita site (Figure 5).

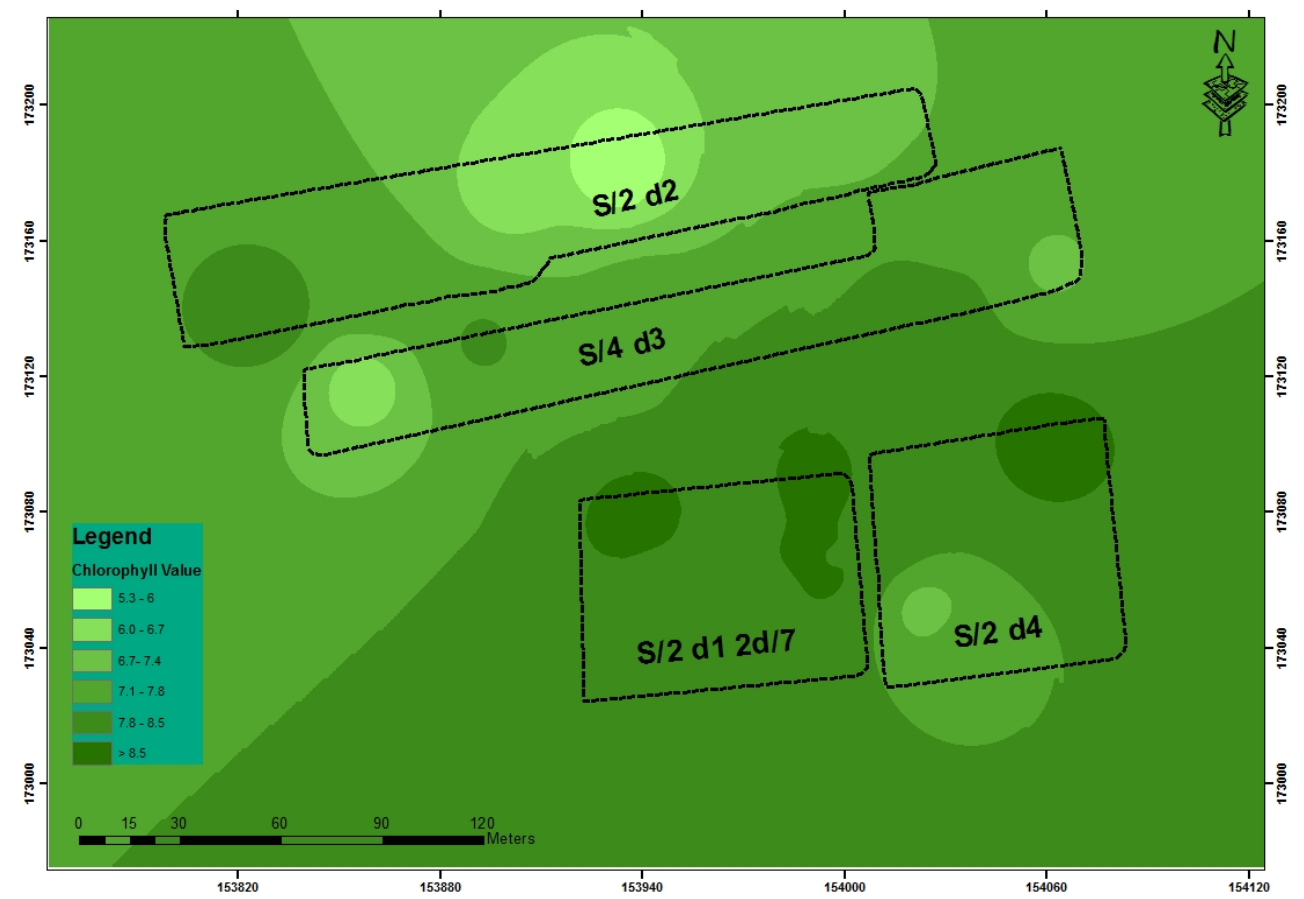

Figure 3: Spatial distribution of chlorophyll in Kuruwita site (Interpolation was based on IDW method).

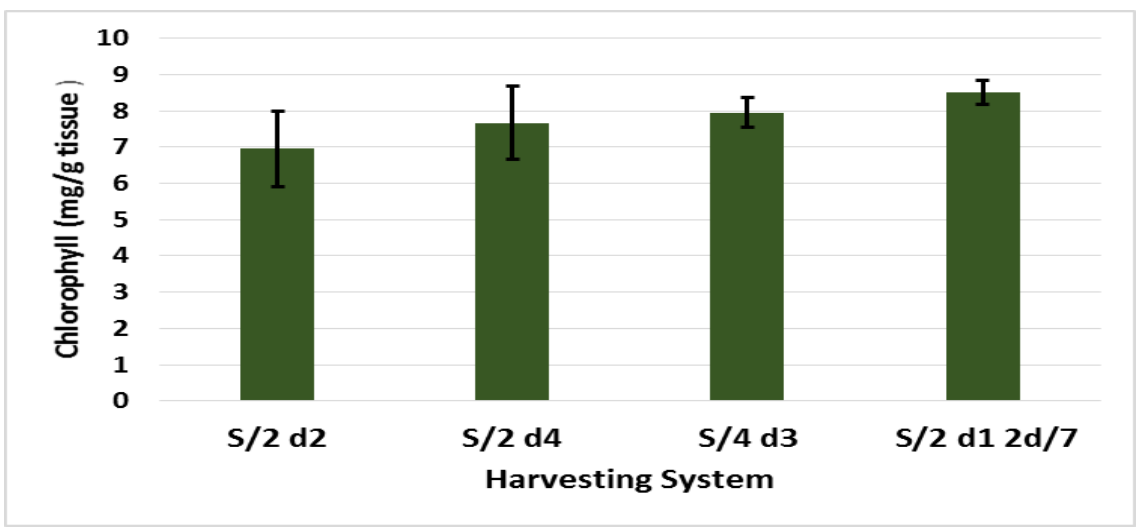

Figure 4: Variation in chlorophyll content in rubber leaves of trees subjected to different harvesting systems. $\mathrm{S} / 2 \mathrm{~d} 2$ - Half spiral based once in two days frequency, $\mathrm{S} / 2 \mathrm{~d} 4$ - Half spiral based once in four days frequency, $\mathrm{S} / 4 \mathrm{~d} 3$ - Quarter spiral based once in three days frequency, $S / 2 d 12 d / 7$ - Tapping the tree once in two consecutive days per week. Values are means of six replicates. Bars represent $\pm \mathrm{SD}$. 


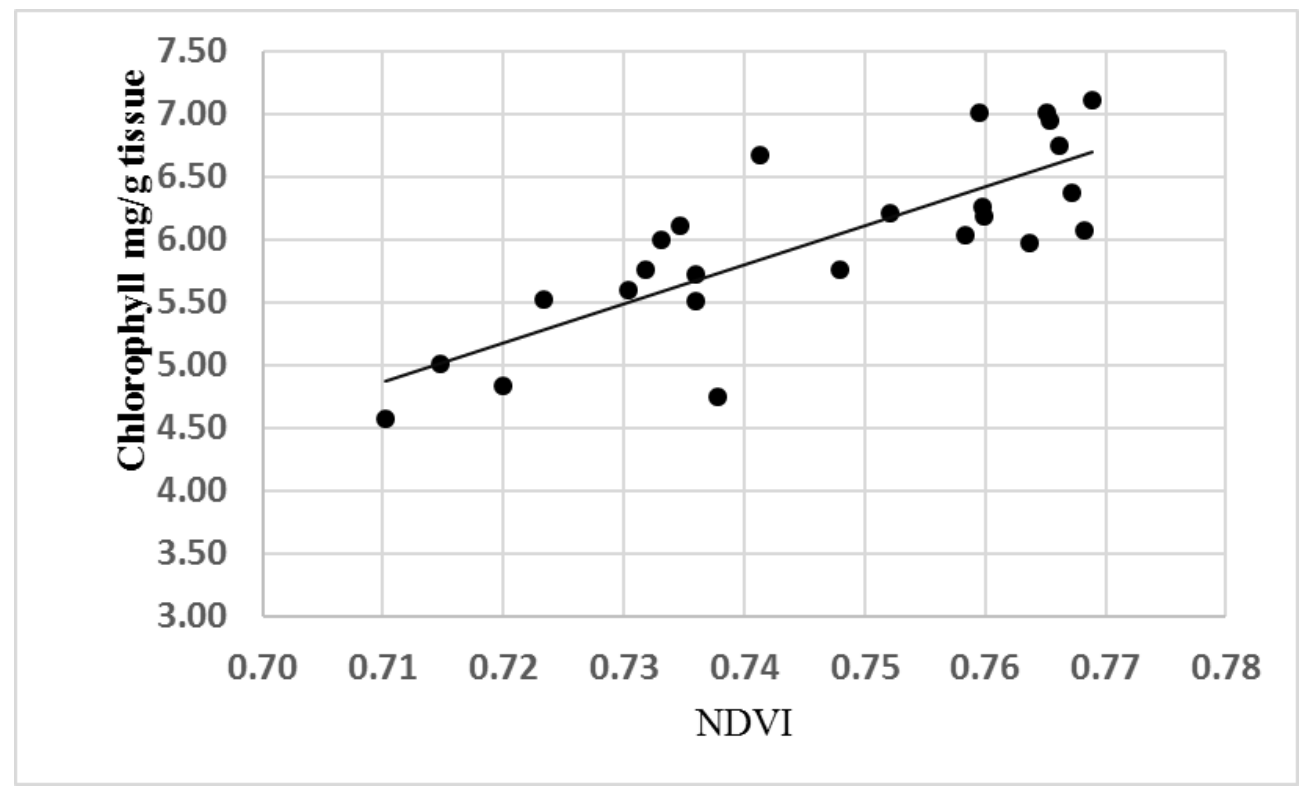

Figure 5: Correlation between normalized difference vegetation index (NDVI) and total chlorophyll content in rubber leaves at Kuruwita experimental site.

\subsection{Rubber yield analysis}

Yields of traditional harvesting system $(\mathrm{S} / 2 \mathrm{~d} 2)$ and low frequency harvesting $(\mathrm{LIH})$ systems $\mathrm{S} / 4 \mathrm{~d} 3, \mathrm{~S} / 2 \mathrm{~d} 4$ and $\mathrm{S} / 2 \mathrm{~d} 12 \mathrm{~d} / 7$ are shown in Figures 6,7 and 8 . GTT was greater in all LIH systems compared to $\mathrm{S} / 2 \mathrm{~d} 2$ system. Both $\mathrm{S} / 2 \mathrm{~d} 4$ and $\mathrm{S} / 2 \mathrm{~d} 12 \mathrm{~d} / 7$ exhibited the highest GTT over five year period. GTT values between LIH systems are not significant but $\mathrm{S} / 2 \mathrm{~d} 4$ shows insignificantly lower value (Figure 6).

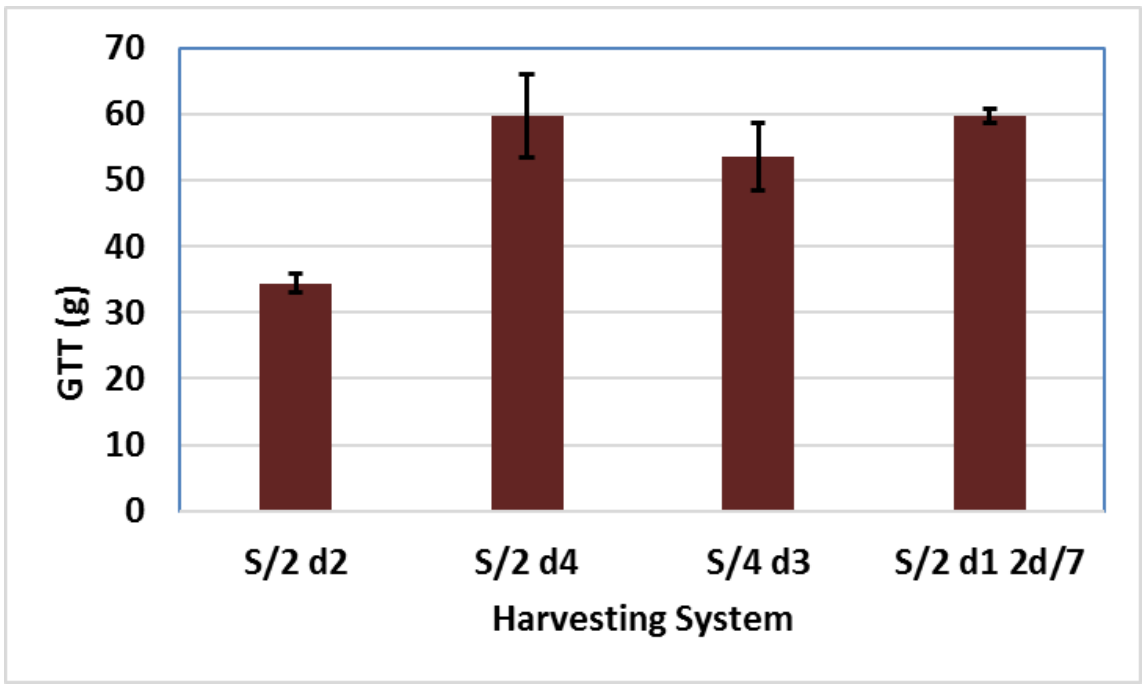

Figure 6: GTT of four harvesting systems in five year period (2012-2016). GTT (g) (Daily dry rubber yield per tree).Values are means of five years. Bars represent $\pm \mathrm{SD}$. 
S/4 d3 system showed slightly higher production during the five year period (2012-2016) in terms of $\mathrm{YPH}$ compared to $\mathrm{S} / 2 \mathrm{~d} 4$. However, no significant difference between LIH systems and traditional system $\mathrm{S} / 2 \mathrm{~d} 2$ was not observed (Figure 7). $\mathrm{S} / 2 \mathrm{~d} 2$ and $\mathrm{S} / 2 \mathrm{~d} 12 \mathrm{~d} / 7$ systems having same cut length and different frequency of tapping maintained more or less same yields over the years.

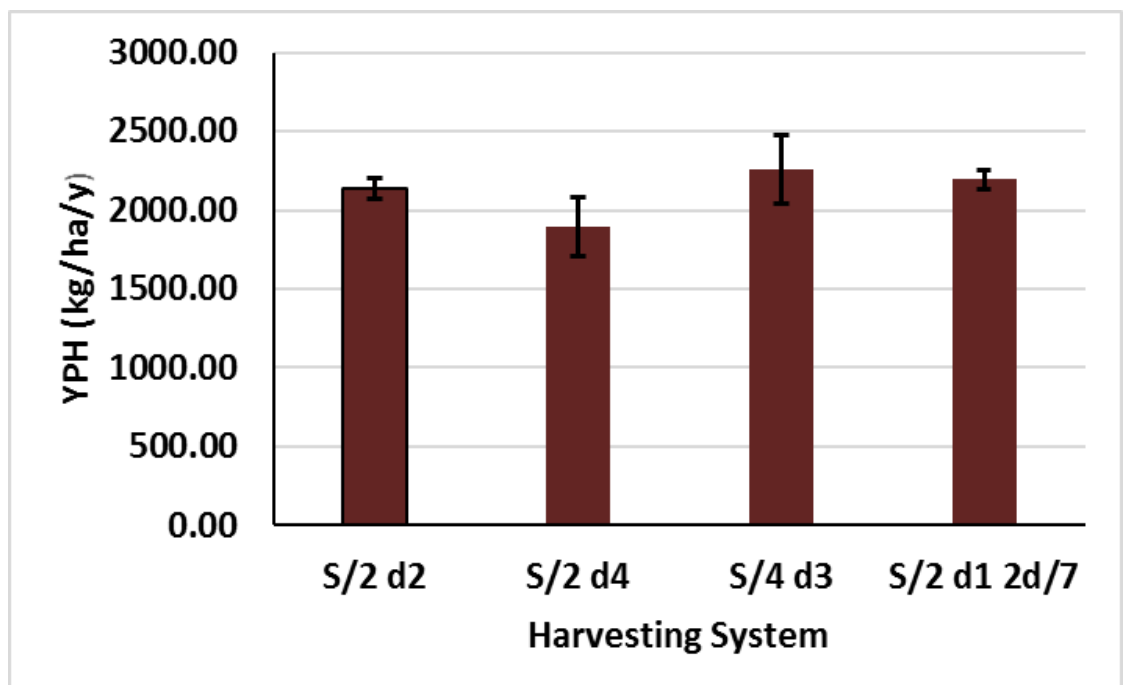

Figure 7: Yield per hectare per year (YPH) in different harvesting systems in five year period (2012-2016). Values are means of five years. Bars represent \pm SD.

Dry rubber content of latex did not show significant difference between different harvesting systems though $\mathrm{S} / 4 \mathrm{~d} 2$ yielded slightly higher DRC\%. All systems maintained an average DRC above 36\% (Figure 8).

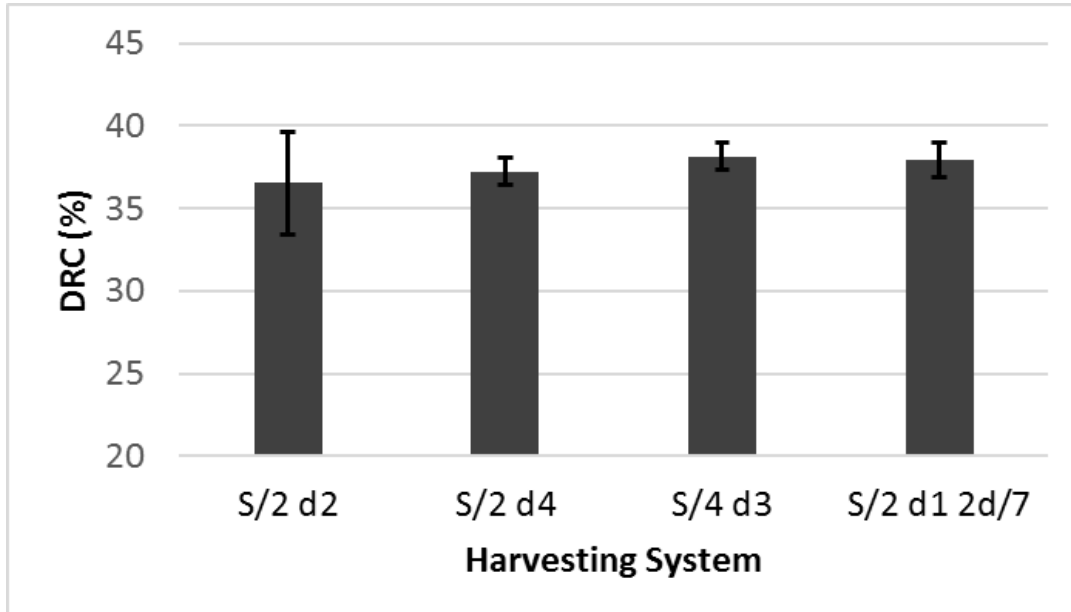

Figure 8: Dry rubber content of latex (DRC \%) of different harvesting systems. Values are means of five years. Bars represent $\pm \mathrm{SD}$.

\section{Discussion}

With the recent development of space technology, Remote Sensing (RS) technology has become a potential tool for assessing the economic potential of rubber cultivation. As chlorophyll content of rubber leaves is an indicator of photosynthetic potential and 
healthiness of a plant, development of an effective and efficient method to assess chlorophyll content of rubber leaves is a vital component of this study.

Observed variation in chlorophyll content in different blocks was attributed to several factors that affect the chlorophyll content of leaves. Sun angle, canopy direction and light intensity are major physical and natural factors that control the chlorophyll content of leaves. NDVI map does not show considerable variation in NDVI values in different blocks, but the variation observed along the rows and canopy is due to combine effect of sun angle and the direction of the rows.

IR and Red energy absorption and reflection have been studied extensively (Gamon and Surfus 1999; Richardson et al., 2002) and presented indices which are well correlated with chlorophyll content of plant leaves (Gitelson et al., 2003). Use of satellite images gives advantages as one of the most significant methods for analysing earth coverage data efficiently and effectively. Thus, RS techniques can cover large view or area and analyse the data very efficiently. Therefore, NDVI analysis which is correlated with in-situ chlorophyll analysis is an effective technique for assessing the productivity of rubber. Present study reveals some positive correlation between NDVI and chlorophyll content of leaves.

Yield performance, in terms of daily dry rubber yield per tree (GTT), dry rubber content of latex (DRC \%), and yield per hectare per year (YPH) over a five year period were evaluated. Though GTT was higher in LIH systems DRC was comparable in all systems. Among tested systems $\mathrm{S} / 4 \mathrm{~d} 3$ is more productive having more chlorophyll and showing increasing trend in $\mathrm{YPH} . \mathrm{S} / 4 \mathrm{~d} 3$ low intensity harvesting system is more profitable for harvesting rubber latex providing benefits; greater yield and reducing production cost and enhancing commercial life span of the tree. In terms of long term productivity $S / 4 \mathrm{~d} 3$ and $S / 2$ d1 $2 \mathrm{~d} / 7$ are promising harvesting systems over $\mathrm{S} / 2 \mathrm{~d} 2$ system in Wet zone cultivations.

The direct correlation between chlorophyll content and yield was observed in trees grown in the experimental plots. Further, NDVI map and chlorophyll distribution map (Figures 2 and 3) illustrate the productive indicators i.e higher chlorophyll content in leaves along with NDVI values in $\mathrm{S} / 4 \mathrm{~d} 3$ and $\mathrm{S} / 2 \mathrm{~d} 12 \mathrm{~d} / 7$ plots. It is an evident for greater yield performance in the $\mathrm{S} / 4 \mathrm{~d} 3$ and $\mathrm{S} / 2 \mathrm{~d} 12 \mathrm{~d} / 7$ plots. LIH systems did not show any adverse effects on physiological functions of trees. All systems performed well producing more than $36 \%$ DRC and comparable YPH. The study reveals $\mathrm{S} / 4 \mathrm{~d} 3$ and $\mathrm{S} / 2 \mathrm{~d} 12 \mathrm{~d} / 7$ adopted well to the modified harvesting systems producing relatively higher yield while reducing tapping labour requirement which in turn increase the economic return of the plantation. Comparable findings were reported by Sumehin et al., 2010 working with clone PR 107, the possibility of reducing the need for tappers and high cost of tapping labour by adopting low frequency tapping or short cut length harvesting system while maintaining the a better vegetation.

The accessible NDVI value could be used as an indicator for chlorophyll level in a plantation. No significant variation in chlorophyll in different harvesting systems was observed. The canopy photosynthesis of rubber is a determining factor of productivity, and that is naturally optimized by partitioning of photosynthetic capacity carrying by the leaves with respect to natural light exposure (Gunasekera et al., 2013). Light significantly affects the total chlorophyll content in rubber leaves. The observed variation in leaf chlorophyll content in the plantation indicates the photosynthetic capacity and productivity of trees growing in different sun angles and directions. 


\section{Conclusion}

Spatial analysis of chlorophyll and satellite image data (NDVI) indicate the sound physiological balance of trees and healthiness of the rubber plantation. Correlation to Chlorophyll to NDVI is more or less same as correlation of leaf chlorophyll content and the latex yield. Thus use of satellite based remote sensing technique is an easy and efficient tool to estimate potential rubber production in different harvesting systems in plantations at any scale.

\section{Acknowledgement}

We wish to thank University of Sri Jayewardenepura for granting funds (Grant No. ASP/06/RE/SCI/2013/02) and Rubber Research Institute, Sri Lanka for providing facilities to carry out this research project. Every support given by Mr. Randunu and staff of the Department of Biochemistry and Physiology, RRI are also kindly acknowledged.

\section{Reference}

Arnon, D.I., 1949. Copper enzymes in isolated chloroplasts, polyphenoloxidase in Beta vulgaris. Plant Physiology. 24, 1-15.

Chen, B., Wu, Z., Wang, J., Dong, J., Guan, L., Chen, J., Yang, K., Xie, G., 2015. Spatiotemporal prediction of leaf area index of rubber plantation using HT-1A/1B CCD image and recurrent neural network. ISPRS Journal of Photogrammetry and Remote Sensing. 102, 148-160.

Coops, N.S., Stine, C., Culvenor, D. S., Chisholm, L.A., Merton, R.N., 2003. Chlorophyll content in eucalypt vegetation at the leaf and canopy scales as derived from high resolution spectral data. Tree Physiology. 23, 23-31.

Danks, S.M., Evans,E., Wittaker, P.A., 1983. Structure, function and assembly. In Photosynthetic Systems. 15-17. New York, N.Y.: Wiley.

Gaman, J.A., Surfus, J.S.C., 1999. Assessing leaf pigment content and activity with a reflectometer. New Phytologist.143, 105-117.

Gunasekera, H.K.L.K., De Costa, W.A.J.M., Nugawela, A., 2013. Canopy photosynthetic capacity and light response parameters of rubber (Hevea brasiliensis) with reference to exploitation. Current and Agricultural Research Journal.1 (1), 01-12.

Johari, H., James, N., Sivakumaran, S., Yong, H.W., Muthu, K. , 1993. Productivity and economics of enlarged tasks - A case study. Planter's Bulletin, Rubber Research Institute of Malaysia. 214, 26-37.

Jones, C.T., Weckler, P.R., Maness, N.O., Jayasekera, R., Stone, M.L., Chiz, D., 2007. Remote sensing to estimate chlorophyll concentration in spinach using multi-spectral plant reflectance. American Society of Agricultural and Biological Engineers. 50 (6), 2267-2273.

Kudaligama, K.V.V.S., 2013. Effectiveness of low intensity tapping suitable for rubber (Hevea) grown in the low country wet zone of Sri Lanka. PhD Thesis, University of Sri Jayewardenepura.

Kudaligama, K.V.V.S., Rodrigo, V.H.L., Fernando, K.M.E.P., Yapa, P.A.J., 2013. Response of RRIC 121 clone to low frequency harvesting systems in the intermediate zone of Sri Lanka. Proceedings of Young Scientists Forum Symposium 2012, Colombo, Sri Lanka. 24. 
Lacote R., Obouayeba, S., Clement-Demange, A., Dian, K., Gnagne, M, Gohet, E., 2004. Panel management in rubber (Hevea brasiliensis) tapping and impact on yield, growth and latex diagnosis. Journal of Rubber Research. 7,199-217.

Nugawela, A., Long, S.P., Aluthhewage, R.K., 1995. Possible use of certain physiological characteristics of young Hevea plants in predicting yield at maturity. Journal of Natural Rubber Research.10, 266-275.

Nugawela, A., Peries, M.R.C., Wijesekera, S. and Samarasekera, R.K., 2000. Evaluation of $\mathrm{d} / 3$ tapping with stimulation to alleviate problems related to $d / 2$ tapping of Hevea. Journal of the Rubber Research Institute of Sri Lanka. 83, 49-61.

Richardson, A.D., Duigan, S.P., Berlyn, G.P., 2002. An evaluation of noninvasive methods to estimate foliar chlorophyll content. New Phytologist. 153, 185-194.

Rodrigo, V.H.L. 2007. Ecophysiologicl factors underpinning productivity of Hevea brasiliensis. Brazilian Journal of Plant Physiology. 19(4), 245-255.

Rodrigo, V.H.L., Kudaligama, K.V.V.S., Fernando, K.M.E.P., Yapa, P.A.J., 2011. Harvesting the rubber tree once in four days: a solution to the current issues in the rubber industry in Sri Lanka. Journal of Rubber Research Institute of Sri Lanka. 91, $15-35$.

Rodrigo, V.H.L., Kudaligama, K.V.V.S., Fernando, K.M.E.P, Yapa, P.A.J., 2012. Replacing traditional half cut by a quarter cut with ethephon; a simple approach to solve current issues related to latex harvesting in rubber industry. J. Natn. Sci. Foundation Sri Lanka .40 (4)283-291.

Rodrigo, V.H.L., Wickramarathna, N.A.A.D., Vidanapathirana, R.D., 2004. Productivity and tapper shortage in rubber plantations; Low frequency tapping can address the shortage of tappers in rubber plantations of Sri Lanka. Proceedings of the First Symposium on Plantation Crop Research, Colombo, Sri Lanka. 32-42.

Sivakumaran, S., Ahamad, Z., Chong, K., 1991. Periodic tapping systems- A solution for tapper shortage. Planters' Bulletin, Rubber Research Institute of Malaysia. 208/209, 111-123.

Sivakumaran, S., Nayagam J., Chong, K., Yong, H.W., 1993. Economics of tapping rubber tree once a week. Planters' Bulletin, Rubber Research Institute of Malaysia. 214, 17 25.

Sumahin, E.F., Obouayeba, S., Dick, K.E., Dogbo, D.O., Anna, A.P. 2014. Low intensity tapping systems applied to clone PR 107 of Hevea brasiliensis (Muell. Arg.): Results of 21 years of exploitation in South-eastern Côte dilvoire. African Journal of Plant Science. 4(5), 145-153.

Vijayakumar, K.R., 2003.Low intensity tapping to reduce cost of natural rubber production. Indian Rubber Journal. 70, 41-42.

Yoder, B.J., Pettigrew -Crosby, R.E., 1995. Predicting nitrogen and chlorophyll content and concentration from reflectance spectra $(400-500 \mathrm{~nm})$ at leaf and canopy scale. Remote Sensing Environment. 53, 199-211.

Yoder, B.J., Waring, R.H. 1994. The normalized difference vegetation index of small Douglas-fir canopies with varying chlorophyll concentrations. Remote Sensing Environment. 49, 81-94. 